\title{
Sargramostim Plasmid DNA Hepatocellular Carcinoma Vaccine Adjuvant
}

National Cancer Institute

\section{Source}

National Cancer Institute. Sargramostim Plasmid DNA Hepatocellular Carcinoma Vaccine

Adjuvant. NCl Thesaurus. Code C48420.

A vaccine adjuvant consisting of a plasmid DNA encoding sarg ramostim (granulocytemacrophage colony-stimulating factor). Upon administration, expressed sarg ramostim may stimulate a cytotoxic $T$ cell response enhancing the host immune response to a concomitantly administered hepatocellular carcinoma vaccine. ( $\mathrm{NCI05)}$ 